\title{
Social Influence Scale for Technology Design and Transformation
}

\author{
Agnis Stibe $^{1}$ and Brian Cugelman ${ }^{2,3}$ \\ ${ }^{1}$ ESLSCA Business School Paris, France \\ agnis@transforms.me \\ ${ }^{2}$ Statistical Cybermetrics Research Group, University of Wolverhampton, UK \\ ${ }^{3}$ AlterSpark, Toronto, ON, Canada \\ brianealterspark.com
}

\begin{abstract}
Contrary to popular belief, social influence encompasses a much more complex area of behavioral science than the explanation offered by those who call all forms of social influence a social norm, peer pressure, or simply social proof. To help scholars and practitioners develop a deeper understanding of social influence, this study presents a measurement instrument for evaluating susceptibility to seven social influence principles, namely social learning, social comparison, social norms, social facilitation, social cooperation, social competition, and social recognition. Each principle is represented by a construct containing six theory-driven items, both positively and negatively framed. Further, the study introduces a social influence research model that describes how the seven social influence constructs are correlated and impact each other. This study extends previous scientific work on social influence by providing research tools that can be used to further study the role of social influence in designing tailored technologies for transformation.
\end{abstract}

Keywords. Social Influence, Transformation, Persuasive Technology, Design, Behavior Change, Human-Computer Interaction, Socially Influencing Systems

\section{$1 \quad$ Introduction}

This work is emerging as an inevitable response to the ever-growing imbalance in our lives across the globe [42]. Over the decades, advanced technologies are researched designed to make our lives better [1] and businesses growing. The fundamental question still remains: with all the evolving innovations, are we gaining decent success in achieving happier societies [8] and solid organizations?

Every crucial domain of our lives continuously provides evidence of how things are getting imbalanced despite us making huge progress in building increasingly capable technological innovations, such as artificial intelligence, blockchain, augmented reality, autonomous vehicles, and drones, just to name a few. This work summarizes the state-of-the-art scientific insights and applicable research tools to transform lives and businesses globally. 
Research on designing technologies that influence people's beliefs, attitudes, and behaviors, has been steadily advancing for more than a decade after the release of the seminal book on persuasive technology by Fogg [18]. Scholars have been continuously expanding and providing various taxonomies, lists of influence principles, and design techniques for behavior change and transformation, e.g., Cugelman et al. [12], Harjumaa [21], Michie et al. [30], Stibe [44], and others.

Although these taxonomies are all focused on using technology to influence what people think and do, their character and qualities differ, as recently highlighted by Stibe et al. [42] in their work on transforming wellbeing theory. Persuasive and transforming technologies influence users' attitudes and behaviors using a variety of principles from behavioral psychology, particularly those from persuasion and social influence.

The terms persuasion and social influence are often used interchangeably when explaining how someone's behavior or attitudes are changed by the influence of other people [45]. Although both can influence people's attitudes and behaviors, earlier research suggests that persuasion and social influence operate through distinct mechanisms [22] [23], and therefore should be applied with an understanding of each distinct approach.

According to Wood [52], on the one hand persuasion typically relies on detailed argumentation presented to people without engaging in active social interaction. On the other hand, social influence is usually present and becomes possible within active and complex social settings. O'Keefe [34] has argued that persuasion mainly is built upon reasoning and argument to steer people according to a desired agenda, but social influence is commonly enabled and facilitated by the behavior and actions of surrounding people. Further, Stibe et al. [42] have explained that, in contract to traditional tactics of persuasion, social influence can serve as much stronger catalyst for achieving sustainable changes, i.e. transformation.

\section{Research Questions}

Social influence describes the psychological principles that exert various effects on people's attitudes and behaviors through the actual, imagined, or implied presence of other people [39]. Often, social influence is also addressed in relation to areas of minority influence in group settings, dynamic social impact theory, expectation states theory, and persuasion [11].

Social norms and social proof have been the most commonly used terms to describe influence effects. However, according to Stibe et al. [43-47], there is far more diversity and depth to social influence that what is conventionally described by these popular terms.

For these reasons, this study further investigates the multifaceted nature of social influence by addressing the following research questions:

- RQ1: What measurement instrument can help assess and evaluate each distinct social influence principle?

- RQ2: How do the social influence principles relate to each other? 
To address these research questions, this study reviews relevant background literature, develops and presents a measurement instrument for studying social influence principles, tests and validates a new social influence scale though an online survey, and then introduces a social influence research model that describes how social influence principles impact each other when used simultaneously.

\section{Socially Influencing Systems}

Over the last years, many scholars have studied social influence in numerous persuasive and transforming technology applications. Stibe [43-45] introduced a framework for Socially Influencing Systems (SIS), which has been used to design and evaluate technology that improves employee engagement in bicycling to work [31] [46]. Oyibo and Vassileva [37] have used the SIS framework to investigate social predictors of competitive behavior. Orji [35] has employed it to support an exploration of the strengths and weaknesses of socially-oriented persuasive strategies.

The SIS framework has been applied to studies on design choices for health behavior change [32], persuasive strategies to encourage low-energy mobility [53], cocreation for living mobility [5], digital games for social persuasion to prevent speeding [28], and persuasive practices for home security advisory services [16]. It has also been used by Myneni and Iyengar [33] to study health promotion technology, WaisZechmann et al. [50] on investigating the personalized strategies, and Hamari et al. [20] for gamification.

The seven principles of social influence within the SIS framework were derived from multiple studies and theories across the social sciences, social psychology, and other disciplines. The following seven sub-sections introduce each principle, provide background, and illustrate how to apply each principle. Fig. 1 provides a graphical representation of the seven principles and their dominant sub-dimensions.

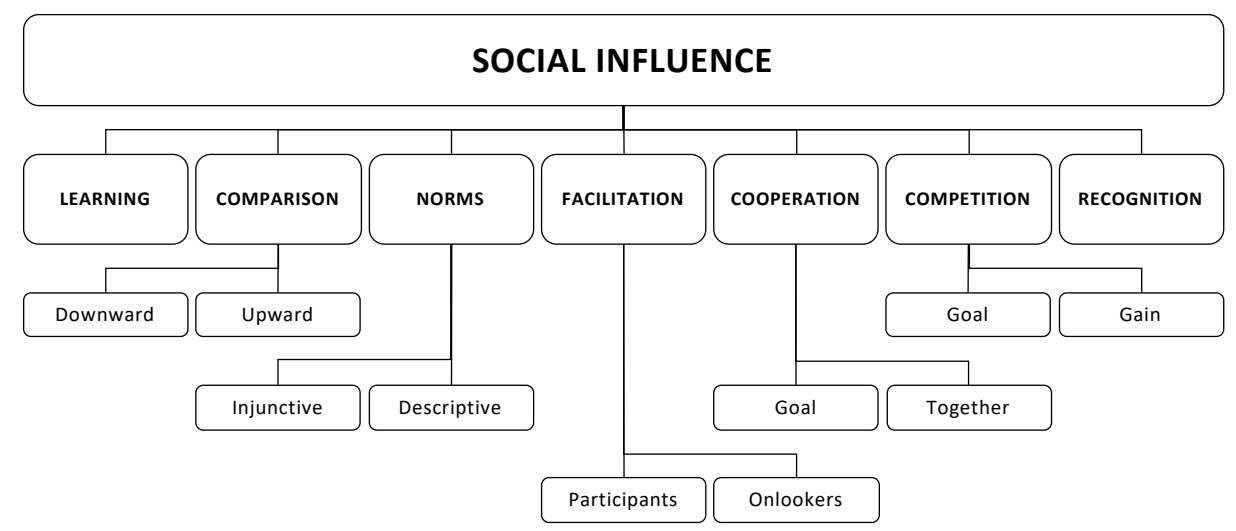

Fig. 1. Seven social influence principles with their sub-dimensions. 


\subsection{Social Learning}

Within a social context, people learn from others by observing their behaviors [3]. This implies that the transmission of information from one individual to another happens through imitation, teaching, and spoken or written language. According to Bandura [3], social learning is ubiquitous and potent because it allows people to avoid the costs of individual learning. Essentially, social learning is about learning new behaviors by watching others perform them. An example includes enabling users of a transforming technology to see others are using it, when, how long, and in what way. Social learning is frequently employed by "how-to" videos that demonstrate someone performing each step in a process.

\subsection{Social Comparison}

When people use information about others to evaluate themselves, they engage in social comparison [17]. More precisely, social comparison is defined as the process of thinking about others in relation to oneself [51]. This process influences motivation, as people look for self-enhancement when comparing themselves with others who are worse off, or they look for self-improvement when seeking a positive example for comparison. In short, social comparison emerges as soon as an individual compares his or her behavior with others who are performing the same behavior in the same context.

An example includes a transforming technology that displays the names of active users in larger font sizes, compared to infrequent users whose names are represented in small fonts. Many gamification design patterns employ leaderboards, which force users into a social comparison ranking system, and these are often implemented without an understanding of negative social comparison, as the bottom of the leader board is a backfire design pattern called a 'loser board', a source of negative social comparison.

\subsection{Social Norms}

When someone follows the behavior of other people in order to be liked and accepted, they are under the influence of social norms [15]. Social norms explain why people tend to follow societal conventions and experience peer pressure. They are shaped by the perception that a particular way of acting is popular among other people. Studies emphasize that both injunctive and descriptive norms are particularly effective in altering peoples' behaviors and attitudes. Injunctive norms inform people about what they ought to do, whereas descriptive norms refer to what most people actually do [10]. Transforming technology can apply social norms with techniques as simple as describing the behavior of other users in a particular context. 


\subsection{Social Facilitation}

The mere or imagined presence of people in social situations creates an atmosphere of evaluation, which enhances users' performance, speed, and accuracy of well-practiced tasks, but reduces their performance for less familiar tasks. Social facilitation effects occur in the presence of both passive onlookers and people who are actively engaged in the same activity [54]. At its core, social facilitation emerges when an individual is surrounded by others who are co-performing or watching what he or she is doing. For example, a transforming technology can show users who are engaged in a common task, that other people are able to see what they are doing.

\subsection{Social Cooperation}

Social cooperation is an activity aimed at working together or achieving a common goal. This interpersonal factor provides important intrinsic motivation that would not be present in the absence of other people [26]. Cooperation is directed toward the same social end by at least two individuals [29]. On a social level, people cooperate when they are working together, or when they are striving to achieve common goals. With independent tasks, combining the progress of different people can encourage cooperation [26]. An example of applications in transforming technology is highlighting how much all users have achieved together.

\subsection{Social Competition}

Another interpersonal factor that provides important intrinsic motivation in social contexts is social competition [26]. People compete when they are striving to achieve the same goal that is scarce or when they seek to gain the same outcome that another person is pursuing. When independent tasks are accompanied by metrics that inform users about the performance of others, this creates a competitive environment where users can compare their performances against others [26]. For example, a transforming technology can show an ordered list of users based on their achievements, with a special place for the most successful users.

\subsection{Social Recognition}

People experience a positive emotional reward of social recognition after receiving an acknowledgement for success related to competing or cooperating with others [41]. In other words, recognition can be described as a value that individuals derive from gaining public appreciation and acknowledgement from others in front of an audience. For example, a transforming technology can provide or assign special titles (as badges of honor) in a way that is visible to all the other users. 


\section{Social Influence Scale}

Despite growing research on the use of social influence in technology design and transformation, scholars lack suitable measurement tools, which limits their ability to conduct empirical studies on social influence. Thus, the study here addresses the first research question.

RQ1: What measurement instrument can help assess and evaluate each distinct social influence principle?

Whereas prior social influence scales have been developed to help researchers assess which social influence principles are being applied in a given technology [43-46], the social influence scale in this paper measures personal differences in susceptibility to social influence principles. This extends the method applied previously, which measured susceptibility to persuasion [24].

In developing the current scale, the authors began by pooling psychometric constructs and indicators from social influence scales previously introduced by Stibe et al. [43-46]. These prior studies were used to frame the constructs for each social influence principle and their respective measurement items.

Working within these frameworks and drawing on literature from social psychology, the authors developed survey items focused on identifying personality-based predisposition towards particular social influence principles, based on emotional, cognitive and behavioral differences between people.

Table 1 lists the seven constructs, each with six indicator items, both positively and those with a $\left(^{*}\right)$ being negatively framed, for measuring and assessing each construct, along with their combined factor loadings.

Table 1. The social influence scale and combined loadings.

\begin{tabular}{llr}
\hline Construct & Items & Load \\
\hline \multirow{5}{*}{ Social } & I prefer learning new things by watching others & .821 \\
Learning & I learn new skills by observing others & .858 \\
& I learn new skills by watching others & .608 \\
& To improve my skills, I learn best by observing others & .669 \\
& I don't learn by watching others * & .857 \\
& I don't watch others to learn new things * & .866 \\
\hline & I don't compare myself to other people * & .922 \\
Social & I compare myself to other people & .829 \\
Comparison & I frequently compare how I am doing, relative to other people & .921 \\
& I am uninterested in comparing myself against others * & .887 \\
& I never compare myself to other people * & .796 \\
& I assess my performance against others & .907 \\
\hline \multirow{3}{*}{ Social } & I prefer to do what other people typically do & .762 \\
Norms & I prefer to act the way everyone else is acting & .861 \\
& I follow behaviors that people typically do & .851 \\
& I avoid acting in a way that is uncommon * & .714 \\
& I don't like to do what people typically do * & .734 \\
& I don't copy the behaviors that everyone else does * & .562 \\
\hline
\end{tabular}




\begin{tabular}{|c|c|c|}
\hline \multirow{6}{*}{$\begin{array}{l}\text { Social } \\
\text { Facilitation }\end{array}$} & $\begin{array}{l}\text { When I realize people are working on something important to me, I } \\
\text { also want to start doing it }\end{array}$ & .880 \\
\hline & $\begin{array}{l}\text { When people are doing something that interests me, I think about } \\
\text { doing it also }\end{array}$ & .846 \\
\hline & $\begin{array}{l}\text { When I see people doing something that inspires me, I want to do it } \\
\text { as well }\end{array}$ & .392 \\
\hline & $\begin{array}{l}\text { When I see people doing something I'm interested in, I feel like } \\
\text { doing it too }\end{array}$ & .608 \\
\hline & $\begin{array}{l}\text { When I observe people doing something important to me, it has no } \\
\text { impact on my desire to start* }\end{array}$ & .830 \\
\hline & $\begin{array}{l}\text { When I see people doing something relevant to me, I feel no desire } \\
\text { to start doing it* }\end{array}$ & .853 \\
\hline \multirow{6}{*}{$\begin{array}{l}\text { Social } \\
\text { Cooperation }\end{array}$} & I don't like to collaborate with people * & .917 \\
\hline & I enjoy collaborating with people & .856 \\
\hline & I like to co-create with others & 697 \\
\hline & I like to build things with other people & .858 \\
\hline & I avoid invitations to collaborate with people $*$ & .766 \\
\hline & I enjoy working with other people, rather than working alone & .903 \\
\hline \multirow{6}{*}{$\begin{array}{l}\text { Social } \\
\text { Competition }\end{array}$} & I dislike competitions * & .911 \\
\hline & I don't like to compete with people * & .921 \\
\hline & I enjoy participating in competitions & .902 \\
\hline & I am not a competitive person by nature * & .911 \\
\hline & I enjoy competing with others & .875 \\
\hline & I am a competitive person & .855 \\
\hline \multirow{6}{*}{$\begin{array}{l}\text { Social } \\
\text { Recognition }\end{array}$} & I don't like to receive acknowledgements in public * & .893 \\
\hline & I enjoy when my achievements are acknowledged in public & .936 \\
\hline & $\begin{array}{l}\text { I would rather avoid being recognized in public for my achieve- } \\
\text { ments * }\end{array}$ & .931 \\
\hline & I like to be honored in public & .904 \\
\hline & $\begin{array}{l}\text { I feel exited when I am publicly recognized for my accomplish- } \\
\text { ments }\end{array}$ & .868 \\
\hline & I don't want my achievements to be recognized in front of others * & .803 \\
\hline
\end{tabular}

\section{$5 \quad$ Data Collection and Scale Validation}

The social influence scale was developed through two stages, including three studies with exploratory factor analysis and confirmatory structural equation modelling. The first and second studies employed exploratory factor analysis to identify the factor structure. The third employed a confirmatory study to assess the scale overall goodness of fit.

In all studies, participants were recruited from Amazon's Mechanical Turk, within the United States. In each study, participants responded to statements using sevenpoint semantic differential scales, with the option of responding "I cannot say". Survey design followed standards for web-based surveys [14]. All questionnaires included attention and fraud detection tests, to identify insincere respondents, based on standard practice for ensuring quality samples from the Mechanical Turk [9]. 


\subsection{Exploratory Factor Analysis}

The first two studies employed exploratory factor analysis [36] for scale development, with a focus on evaluating item comprehension and validating construct validity. The first study ran in early February 2018 with 162 participants, the removal of 26 responses that were incomplete or failed our attention tests, leaving 136 responses for analysis. The second study ran in late February 2018 with 151 participants, with 16 removed for failing to pass our attention tests, leaving 135 for the analysis.

\subsection{Confirmatory Structural Equation Modelling}

The third study employed confirmatory structural equation modelling to assess the scale's theoretical relationships, construct validity and overall model fit. The final online questionnaire ran in March 2018 and collected feedback from 165 participants. After removing 22 responses that were incomplete or failed our attention tests, 125 responses were included in the final analysis.

Among the participants, there were 69 females (55.2\%) and 56 males (44.8\%). The age of the participants ranged between 21 and 82 years, with the mean age being 44 years. All of these participants marked that they understood and spoke English fluently like a native speaker. The data was analyzed with partial least squares structural equation modeling (PLS-SEM) using WarpPLS 6.0 software. This method was selected because it well suits the needs of exploratory research and is appropriate for predictive approach rather than testing an established theory [19]. Data analysis with PLS-SEM included both assessment of the reliability and validity of the measurement model and assessment of the structural model.

The measurement model includes the relationships between the constructs (Table 2 ) and the indicators used to measure them (Table 1). The measurement instrument for this study was developed based on the theory-driven items, which were pretested with two scholars of transforming technology and through two rounds of pilot studies involving 271 participants. Further, the properties of the developed scale were assessed in terms of item loadings, discriminant validity, and internal consistency, where item loadings and internal consistencies greater than .70 are considered acceptable (Table 2).

The constructs in the model display good internal consistency, with composite reliability scores ranging from .88 to .96 . Inspection of the construct correlations and square root of the average variance extracted in Table 2 demonstrate that all constructs share more variance with their own items than with other constructs, thus providing support for internal consistency of the factor structures.

\section{Social Influence Model}

By better understanding how social influence principles are related to one another, researchers will be better equipped to study social influence, while practitioners will be better equipped to apply it. This section addresses the second research question.

RQ2: How do the social influence principles relate to each other? 
To answer this question, the structural model of social influence (Fig. 2) originated from and was shaped upon the strongest correlations between constructs, which were observable from the measurement model (Table 2), and previous scientific literature on the SIS framework [43-46] supporting the emerging relationships.

Table 2. Latent variable coefficients and correlations.

\begin{tabular}{|c|c|c|c|c|c|c|c|}
\hline & COOP & CMPE & NORM & RECO & CMPA & FACI & LEAR \\
\hline COR & .93 & .96 & .89 & .96 & .95 & .88 & .91 \\
\hline CRA & .91 & .95 & .85 & .95 & .94 & .84 & .87 \\
\hline AVE & .70 & .80 & .57 & .79 & .77 & .57 & .62 \\
\hline VIF & 1.6 & 1.4 & 1.5 & 1.4 & 1.5 & 1.7 & 1.6 \\
\hline COOP & .84 & & & & & & \\
\hline CMPE & .32 & .90 & & & & & \\
\hline NORM & .33 & .16 & .75 & & & & \\
\hline RECO & .44 & .41 & .21 & .89 & & & \\
\hline CMPA & .18 & .38 & .33 & .35 & .88 & & \\
\hline FACI & .42 & .29 & .44 & .30 & .42 & .76 & \\
\hline LEAR & .36 & .01 & .48 & .14 & .28 & .48 & .79 \\
\hline $\mathrm{CO}$ & $\begin{array}{c}\text { Bolded } \\
=\text { cooper } \\
\mathrm{CMF}\end{array}$ & $\begin{array}{l}=\text { compc } \\
\text { IF = vari } \\
\text { sonal = s } \\
\text { in CMPI } \\
=\text { compa }\end{array}$ & $\begin{array}{l}\text { e reliabili } \\
\text { ce inflatio } \\
\text { are root of } \\
\text { competit } \\
\text {; FACI }\end{array}$ & $\begin{array}{l}\mathrm{CRA}= \\
\text { actor (fu } \\
\text { rerage va } \\
\text {; NORM } \\
\text { acilitatio }\end{array}$ & $\begin{array}{l}\text { nbach's } \\
\text { ollinearit } \\
\text { ace extra } \\
\text { norms; R } \\
\text { EAR }=\end{array}$ & $\begin{array}{l}(\mathrm{AVE}) \\
\mathrm{O}=\mathrm{rec} \\
\text { hing }\end{array}$ & tion \\
\hline
\end{tabular}

In the analysis of the research model, a PLS mode $\mathrm{M}$ regression algorithm was used, in which the measurement model weights were calculated through a least squares regression, where the latent variable or construct score is the predictor and the indicators or items are the criteria [25]. As it can be observed from Fig. 2, the results of the PLS-SEM analysis provide substantial support for the structural research model. It reveals that the seven social influence features are intricately interconnected.

Social facilitation is the only independent construct having no inbound arrows in the social influence model. Social facilitation has direct arrows pointing to four other constructs, i.e. social comparison, social cooperation, social learning, and social norms. In the social influence model, social facilitation alone explains $18 \%$ of the variance in social comparison, which explains $16 \%$ of the variance in social competition, which explains $17 \%$ of the variance in social recognition. Further, social facilitation and social recognition equally contribute in explaining $30 \%$ of the variance in social cooperation. Both, social facilitation and social cooperation together are explaining $31 \%$ of the variance in social learning, where social facilitation provides a larger contribution of $21 \%$, comparing to $10 \%$ of variance from social cooperation. social facilitation and social learning together explain $30 \%$ of the variance in social norms, but in this case, social learning turns out to be larger contributor by explaining $18 \%$ as compared to $12 \%$ coming from social facilitation. 


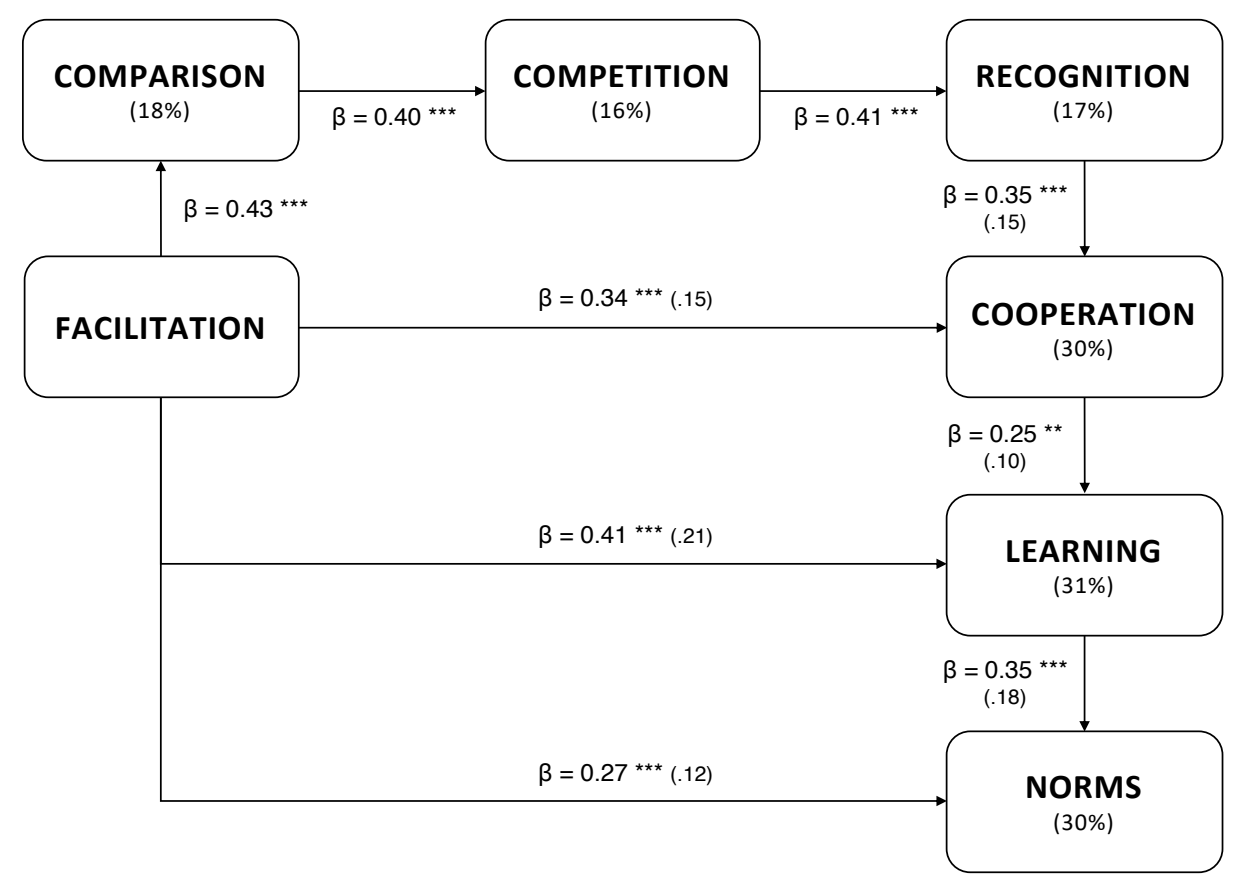

Fig. 2. The social influence model overlaid with the PLS-SEM analysis results.

The $\beta$ values attached to each arrow (Fig. 2) demonstrate the strength of relationships between the constructs and the asterisks mark their statistical significance, while the R-squared contributions are presented in brackets.

Table 3. Total effects and effect sizes.

\begin{tabular}{|c|c|c|c|c|c|c|}
\hline & FACI & CMPA & CMPE & RECO & COOP & LEAR \\
\hline CMPA & $\begin{array}{l}.43^{* * *} \\
(.18)\end{array}$ & & & & & \\
\hline CMPE & $\begin{array}{l}.17^{* *} \\
(.05)\end{array}$ & $\begin{array}{l}.40^{* * *} \\
(.16)\end{array}$ & & & & \\
\hline RECO & $\begin{array}{l}.07 \\
(.02)\end{array}$ & $\begin{array}{l}.17^{* *} \\
(.06)\end{array}$ & $\begin{array}{l}.41^{* * *} \\
(.17)\end{array}$ & & & \\
\hline COOP & $\begin{array}{l}.37^{* * *} \\
(.16)\end{array}$ & $\begin{array}{c}.06 \\
(.01)\end{array}$ & $\begin{array}{l}.14^{*} \\
(.05)\end{array}$ & $\begin{array}{l}.35^{* * *} \\
(.15)\end{array}$ & & \\
\hline LEAR & $\begin{array}{l}.50^{* * *} \\
(.25)\end{array}$ & $\begin{array}{c}.02 \\
(.00)\end{array}$ & $\begin{array}{c}.04 \\
(.00)\end{array}$ & $\begin{array}{c}.09 \\
. .01)\end{array}$ & $\begin{array}{l}.25^{* *} \\
(.10)\end{array}$ & \\
\hline NORM & $\begin{array}{l}.45^{* * *} \\
(.21)\end{array}$ & $\begin{array}{l}.01 \\
(.00)\end{array}$ & $\begin{array}{l}.01 \\
(.00)\end{array}$ & $\begin{array}{c}.03 \\
(.01)\end{array}$ & $\begin{array}{l}.09 \\
(.03)\end{array}$ & $\begin{array}{l}.35^{* * *} \\
(.18)\end{array}$ \\
\hline FACI & $\begin{array}{r}{ }^{* * * *} \mathrm{p} \\
\mathrm{P} \\
\mathrm{COC}\end{array}$ & $\begin{array}{l}01 ;{ }^{* *} \mathrm{p}< \\
\mathrm{C} \text { I has } \mathrm{n} \\
\mathrm{M} \text { has no } \\
\mathrm{PA}=\mathrm{co} \\
\text { cooperat }\end{array}$ & $\begin{array}{l}\mathrm{p}<.05 \\
\text { ound arr } \\
\text { ound arr } \\
\text { son; } \mathrm{CM} \\
\mathrm{EAR}=1\end{array}$ & $\begin{array}{l}\text { Cohen' } \\
\text { ow is bl } \\
\text { olumn } \\
\text { competi } \\
\text { ig; NOR }\end{array}$ & $\begin{array}{l}\text { uared } \\
\text { k) } \\
\text { RECO = } \\
\text { norms }\end{array}$ & snition \\
\hline
\end{tabular}


Table 3 presents a detailed view of the social influence model, with total effects and effect sizes. Effect sizes $\left(\mathrm{f}^{2}\right)$ determine whether the effects indicated by the path coefficients are small (.02), medium (.15), or large (.35).

Additionally, the results of PLS-SEM analysis provide fit and quality indices that support the structural model [25]. Besides reporting the values of average path coefficient $(\mathrm{APC}=.357, \mathrm{p}<.001)$ and average $\mathrm{R}$-squared $(\mathrm{ARS}=.238, \mathrm{p}<.001)$, the model demonstrates a large explanatory power $(\mathrm{GoF}=.405)$. Moreover, both Sympson's paradox ratio $(\mathrm{SPR}=1.000)$ and the nonlinear bivariate causality direction ratio $($ NLBCDR $=1.000)$ provide evidence that the social influence model is free from Sympson's paradox instances, and the direction of causality is supported.

\section{Discussion}

This study has reviewed key principles in social influence and presented a scale for evaluating users' predisposition towards particular social influence principles. The study contributes empirical evidence in support of an advanced social influence scale and demonstrates its structural model. The results also advance the previous work on the SIS framework that has already demonstrated the strength and prominence of social influence principles in designing human-computer interaction and transforming technology [43-46].

This study demonstrated that the seven social influence principles influence each other at various levels. Social facilitation has the capacity to directly trigger and initiate four other principles. This can be explained by the inherent nature of social facilitation [54], as it increases motivation in the presence of other people, which is difficult to avoid in common interactive social technology. Additionally, social facilitation also exhibits a moderate but significant indirect effect on social competition through the mediation of social comparison (Table 3). Social comparison has exhibited its power to directly influence social competition [37], while indirectly affecting social recognition, through a strong and significant relationship. This reinforces earlier observations, that people experience a sense of social competition once they are able to compare their results with the performance of other people in the same context [17] [51]. Quite naturally, an increased desire to see oneself in comparison with others can explain the heightened sensitivity of individuals towards social recognition [26] [46], which arises from people competing for social recognition [26] [29] [41].

Beyond the direct relationship between social competition and social recognition [40], there is a weak but significant indirect effect of social competition on social cooperation that is mediated by social recognition (Table 3). This suggests that there can be occasions, in which social competition and social recognition actually lead to social cooperation [26] [29]. For example, as in the case one extensive bicycling study [46], where the employees of one participating company were cooperating to get their organization to a more competitive position in a ranking, which again implies a sort of recognition for the top companies. Thus, social recognition has shown capacity to drive social cooperation in such and similar contexts. 
According to the social influence research model, social cooperation enables social learning, which is quite understandable, as people tend to observe others in a collaborative setting and adjust their behavior to improve their performance [3]. Social facilitation obviously can help with this, as it provides more insights into the performance of a task, from a broader number of people [54]. Further, through social learning people usually experience normative influence or acquire awareness of new social norms [10] [15]. Again, social facilitation contributes to behavior change by providing more people to teach social norms, causing people to acquire a better understanding of what is normal among the crowd they are learning from.

The present study has developed and introduced an advanced measurement instrument or scale for assessing seven social influence principles. It has also contributed a social influence research model that reveals the strongest correlations between the principles when framed as constructs. Each construct with six validated items (Table 1) can be instrumental for further research and applied transforming design work. Nevertheless, this model should be further evaluated in settings with different combinations of the social influence principles.

In an earlier study by Stibe and Cugelman [47], the misapplication of social influence principles was the most common reason why social and behavioral change programs backfire, producing the opposite outcome, such as anti-drug programs that accidentally trigger the target to increase drug use, rather than decrease it. One explanation is widespread mistaken belief that social influence is limited to social norms or social proof. By better understanding how each social influence principle operates and typically backfires, intervention designers can reduce the risk of misapplying social influence, and instead, design higher impact transforming technologies.

\section{$8 \quad$ Implications}

Present knowledge on persuasive technology reveals how behavior change designs and interventions are often limited in sustaining their effects [42], thus leading mostly to transactional [6] [48] or transitional [2] rather than transformational [42] changes (Table 4). This work on social influence in transforming technology should ultimately empower people and organizations to succeed in their desired and more often even inevitable changes. Scholars and practitioners of human-computer interaction and behavioral computer science [38] can now benefit from novel ways to design technology that helps people not only to achieve their goals, but also to support sustaining their newly developed habits. The proposed social influence scale is extending possibilities for designers to overcome limitations of traditional change management and behavioral designs.

Majority of global problems and business challenges are byproducts of poor human decision-making and unsustainable actions [42]. Communities, societies, businesses, and organizations, basically everyone needs help with transformations [49]. Social influence has already demonstrated its nature to be one of the most persistent motivators for achieving sustainable changes [13] [46]. Thus, the developed social influence scale and research model are very instrumental for change-makers aiming at achiev- 
ing sustainable effects [27], as transformation depends critically on the quality of human-computer interaction [7].

The social influence model helps user experience scholars and practitioners to better understand how their interface design features might exhibit more shades of social influence than the primary chosen principle. For example, whenever a designer would aim at implementing a social comparison principle in a mobile application, that interface will naturally provoke its users to experience a certain degree of social competition, and possibly also social recognition for best performers.

Table 4. Types of change and their characteristics [42].

\begin{tabular}{|c|c|c|c|}
\hline & $\begin{array}{c}\text { Transactional } \\
\text { Change }\end{array}$ & $\begin{array}{c}\text { Transitional } \\
\text { Change }\end{array}$ & $\begin{array}{c}\text { Transformational } \\
\text { Change }\end{array}$ \\
\hline Definition & $\begin{array}{l}\text { An occurrence pro- } \\
\text { ducing an outcome } \\
\text { that differs from pre- } \\
\text { vious preferences. }\end{array}$ & $\begin{array}{l}\text { A period, in which } \\
\text { certain outcomes } \\
\text { significantly differ } \\
\text { from what was } \\
\text { habitual before. }\end{array}$ & $\begin{array}{l}\text { A continuum having direc- } \\
\text { tion as well as magnitude to } \\
\text { produce apparently irre- } \\
\text { versible shifts. }\end{array}$ \\
\hline Description & $\begin{array}{l}\text { To carry on or con- } \\
\text { duct something to a } \\
\text { conclusion or settle- } \\
\text { ment. }\end{array}$ & $\begin{array}{l}\text { Relating to a period } \\
\text { during which some- } \\
\text { thing is changing } \\
\text { from one state or } \\
\text { form into another. }\end{array}$ & $\begin{array}{l}\text { To change completely the } \\
\text { appearance or character of } \\
\text { something or someone, } \\
\text { especially so that that thing } \\
\text { or person is improved. }\end{array}$ \\
\hline Perspective & One-time decision & Durational & Paradigm shift \\
\hline Time & Short-term & Defined-term & Timeless \\
\hline Orientation & Cost-benefit & Goal & Identity change \\
\hline Nature & Bargaining & Achievement & Directional \\
\hline Metric & Decision & Milestone & Personality traits \\
\hline Psychology & Economical & Motivational & Spiritual \\
\hline Example & $\begin{array}{l}\text { Riding a bike to a } \\
\text { park to get free lunch. }\end{array}$ & $\begin{array}{l}\text { Giving up alcohol } \\
\text { for a month. }\end{array}$ & $\begin{array}{l}\text { Becoming a true forgiver } \\
\text { from now on. }\end{array}$ \\
\hline
\end{tabular}

In the realm of interactive technologies for transformation, social influence is competing with and oftentimes demonstrating its supremacy when compared to other conceptual schools of thought, such as gamification and nudging. Due to its scientific richness and practical nature, this work on social influence is applicable in many essential life contexts, including wellbeing, health, innovation, leadership, education, mobility, social change, diversity, culture, governance, automation, emergency, sustainability, autonomy, dwelling, equality, management, marketing, commercialization, safety, energy, ecology, and economy. 


\section{Conclusions}

This study is bridging previous scientific work on social influence to facilitate further advances in transforming technology and human-computer interaction research agendas [4]. The research results can help scholars and designers to eliminate the risks of backfiring due to misapplied behavioral psychology [47]. While many people refer to social influence as a single principle, synonymously called social proof or peer pressure, this study has demonstrated a distinct factor structure that suggests there are psychological details that matter.

The main contribution of this study is three-fold. First, it has reviewed and provided a summary of seven principles or constructs of social influence, which all have distinct characteristics and qualities. Second, it developed and introduced a tool for measuring each construct with six theory-driven items. Third, it demonstrated the interplay among constructs that can explain the potential of each constructs to influence the others.

Limitations of this study include its small sample size, its geographical location, and a few items with low but minimally acceptable factor loadings. For these reasons, the authors caution that additional research is required to further validate the instrument on a larger scale.

As interactive technologies continue to penetrate people's lives at an unprecedent pace, practitioners and researchers will increasingly find themselves making small decisions that have large impacts on individuals and society.

Without a clear understanding of what social influence is, how it works, and what causes it to backfire, the risks that designers and practitioners cause more harm than good is quite high. The authors of this paper hope that with a stronger understanding of what drives social influence among different individuals and populations, they will be empowered to design transforming technologies that lead to better lives and societal wellbeing [42].

\section{References}

1. Alluhaidan, A., Chatterjee, S., Drew, D., Stibe, A.: Sustaining Health Behaviors Through Empowerment: A Deductive Theoretical Model of Behavior Change Based on Information and Communication Technology (ICT). In International Conference on Persuasive Technology (pp. 28-41). Springer, Cham (2018)

2. Amado, G., Ambrose, A.: The Transitional Approach to Change. Karnac Books (2001)

3. Bandura, A.: Social Foundations of Thought and Action: A Social Cognitive Theory. Prentice Hall, Englewood Cliffs, NJ (1986)

4. Bardzell, J., Bardzell, S., Lin, C., Lindtner, S., Toombs, A.: HCI's Making Agendas.

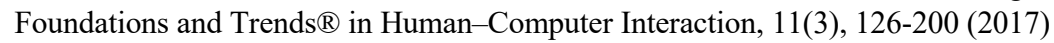

5. Barnes Hofmeister, T., Stibe, A.: Living Mobility Transitions towards Bicycling. Designing Practices through Co-Creation and Socially Influencing Systems. The Design Journal, 20(sup1), S3305-S3316 (2017)

6. Burke, W. W., Litwin, G. H.: A Causal Model of Organizational Performance and Change. Journal of Management, 18(3), pp. 523-545 (1992) 
7. Card, S.K.: The psychology of human-computer interaction. CRC Press (2018)

8. Cecchinato, M.E., Rooksby, J., Hiniker, A., Munson, S., Lukoff, K., Ciolfi, L., Thieme, A., Harrison, D.: Designing for Digital Wellbeing: A Research \& Practice Agenda. In Extended Abstracts of the 2019 CHI Conference on Human Factors in Computing Systems (p. W17). ACM (2019)

9. Chandler, J. J., Paolacci, G.: Lie for a Dime: When Most Prescreening Responses are Honest but Most Study Participants are Impostors. Social Psychological and Personality Science, 8(5), 500-508 (2017)

10. Cialdini, R.B., Kallgren, C.A., Reno, R.R.: A Focus Theory of Normative Conduct: A theoretical Refinement and Reevaluation of the Role of Norms in Human Behavior. Advances in Experimental Social Psychology, 24(20), 1-243 (1991)

11. Crano, W.D., Prislin, R.: Attitudes and Persuasion. Annual Review of Psychology. 57, 345-374 (2006)

12. Cugelman, B., Thelwall, M., Dawes, P.: Online Interventions for Social Marketing Health Behavior Change Campaigns: A Meta-Analysis of Psychological Architectures and Adherence Factors. Journal of medical Internet research, 13(1), e17 (2011)

13. Damon, W.: The Lifelong Transformation of Moral Goals Through Social Influence. Interactive Minds, 198-220 (1996)

14. Dillman, D.A.: Mail and Internet Surveys: The Tailored Design Method. Update with New Internet, Visual, and Mixed-Mode Guide. John Wiley \& Sons (2011)

15. Deutsch, M., Gerard, H.B.: A Study of Normative and Informational Social Influences upon Individual Judgment. The Journal of Abnormal and Social Psychology, 51(3), 629 (1955)

16. Dolata, M., Comes, T., Schenk, B., Schwabe, G.: Persuasive Practices: Learning from Home Security Advisory Services. In International Conference on Persuasive Technology (pp. 176-188). Springer, Cham (2016)

17. Festinger, L.: A Theory of Social Comparison Processes. Human relations, 7(2), 117-140 (1954)

18. Fogg, B. J.: Persuasive Technology: Using Computers to Change What We Think and Do. Morgan Kaufmann, San Francisco (2003)

19. Hair, J.F., Ringle, C.M., Sarstedt, M.: PLS-SEM: Indeed a Silver Bullet. The Journal of Marketing Theory and Practice, 19(2), 139-152 (2011)

20. Hamari, J., Hassan, L., Dias, A.: Gamification, Quantified-Self or Social Networking? Matching users' goals with motivational technology. User Modeling and User-Adapted Interaction, 28(1), 35-74 (2018)

21. Harjumaa, M.: On the Development of Persuasive Systems: A Framework for Designing and Evaluating Behaviour Change Support Systems and its Applicability for e-Health. VTT SCIENCE, 68 (2014)

22. Haslam, S.A., McGarty, C., Turner, J.C.: Salient Group Memberships and Persuasion: The Role of Social Identity in the Validation of Beliefs (1996)

23. Hovland, C.I., Janis, I.L., Kelley, H.H.: Communication and Persuasion. Psychological Studies of Opinion Change (1953)

24. Kaptein, M., Markopoulos, P., De Ruyter, B., Aarts, E.: Personalizing Persuasive Technologies: Explicit and Implicit Personalization Using Persuasion Profiles. International Journal of Human-Computer Studies, 77, 38-51 (2015)

25. Kock, N.: WarpPLS User Manual: Version 6.0. Laredo, TX: Script Warp Systems (2017)

26. Malone, T.W., Lepper, M.: Making Learning Fun: A Taxonomy of Intrinsic Motivations for Learning. In: R.E. Snow and M.J. Farr (eds.) Aptitude, Learning and Instruction: III. Conative and Affective Process Analyses, pp. 223-253. Erlbaum, Hillsdale, NJ (1987) 
27. Maton, K.I.: Making a Difference: The Social Ecology of Social Transformation. American Journal of Community Psychology, 28(1), 25-57 (2000)

28. Maurer, B., Gärtner, M., Wuchse, M., Meschtscherjakov, A., Tscheligi, M.: Utilizing a Digital Game as a Mediatory Artifact for Social Persuasion to Prevent Speeding. In International Conference on Persuasive Technology (pp. 199-210). Springer, Cham (2016)

29. May, M.A., Doob, L.W.: Cooperation and Competition. Social Science Research Council Bulletin, 125 (1937)

30. Michie, S., Richardson, M., Johnston, M., Abraham, C., Francis, J., Hardeman, W., Eccles, M.P., Cane, J., Wood, C. E.: The Behavior Change Technique Taxonomy (v1) of 93 Hierarchically Clustered Techniques: Building an International Consensus for the Reporting of Behavior Change Interventions. Annals of behavioral medicine, 46(1), 81-95 (2013)

31. Millonig, A., Wunsch, M., Stibe, A., Seer, S., Dai, C., Schechtner, K., Chin, R. C.: Gamification and Social Dynamics behind Corporate Cycling Campaigns. Transportation research procedia, 19, 33-39 (2016)

32. Mylonopoulou, V., Väyrynen, K., Stibe, A., \& Isomursu, M.: Rationale Behind Socially Influencing Design Choices for Health Behavior Change. In International Conference on Persuasive Technology (pp. 147-159). Springer, Cham (2018)

33. Myneni, S., Iyengar, S.: Socially Influencing Technologies for Health Promotion: Translating Social Media Analytics into Consumer-Facing Health Solutions. In System Sciences (HICSS), 2016 49th Hawaii International Conference on (pp. 3084-3093). IEEE (2016)

34. O'Keefe, D.J.: Persuasion: Theory and Research. Sage, Newbury (1990)

35. Orji, R.: Why are Persuasive Strategies Effective? Exploring the Strengths and Weaknesses of Socially-Oriented Persuasive Strategies. In International Conference on Persuasive Technology (pp. 253-266). Springer, Cham (2017)

36. Osborne, J.W., Costello, A.B., Kellow, J.T.: Best Practices in Exploratory Factor Analysis. Best Practices in Quantitative Methods, 86-99 (2008)

37. Oyibo, K., Vassileva, J.: Investigation of social predictors of competitive behavior in persuasive technology. In International Conference on Persuasive Technology (pp. 279-291). Springer, Cham (2017)

38. Pedersen, T., Johansen, C., Jøsang, A.: Behavioural Computer Science: An Agenda for Combining Modelling of Human and System Behaviours. Human-Centric Computing and Information Sciences, 8(1), 7.

39. Rashotte, L.: Social Influence. The Blackwell Encyclopedia of Social Psychology, 9, pp. 562-563 (2007)

40. Rottiers, S.: The Sociology of Social Recognition: Competition in Social Recognition Games (No. 1004) (2010)

41. Schoenau-Fog, H.: Teaching Serious Issues through Player Engagement in an Interactive Experiential Learning Scenario. Eludamos. Journal for Computer Game Culture, 6(1), 5370 (2012)

42. Stibe, A., Röderer, K., Reisinger, M., Nyström, T.: Empowering Sustainable Change: Emergence of Transforming Wellbeing Theory (TWT). Adjunct Proceedings of the 14th International Conference on Persuasive Technology (2019)

43. Stibe, A.: Socially Influencing Systems: Persuading People to Engage with Publicly Displayed Twitter-based Systems. Acta Universitatis Ouluensis (2014)

44. Stibe, A.: Towards a Framework for Socially Influencing Systems: Meta-Analysis of Four PLS-SEM Based Studies. In: MacTavish, T., Basapur, S. (eds.) Persuasive Tech-nology, LNCS, vol. 9072, pp. 171-182. Springer, Heidelberg (2015) 
45. Stibe, A.: Advancing Typology of Computer-Supported Influence: Moderation Effects in Socially Influencing Systems. In: MacTavish, T., Basapur, S. (eds.) Persuasive Technology, LNCS, vol. 9072, pp. 251-262. Springer, Heidelberg (2015)

46. Stibe, A., Larson, K.: Persuasive Cities for Sustainable Wellbeing: Quantified Communities. In International Conference on Mobile Web and Information Systems (MobiWIS), pp. 271-282. Springer International Publishing (2016)

47. Stibe, A., Cugelman, B.: Persuasive Backfiring: When Behavior Change Interventions Trigger Unintended Negative Outcomes. In International Conference on Persuasive Technology (pp. 65-77). Springer, Cham (2016)

48. Vito, G. F., Higgins, G. E., Denney, A. S.: Transactional and Transformational Leadership: An Examination of the Leadership Challenge Model. Policing: An International Journal of Police Strategies \& Management, 37(4), pp. 809-822 (2014)

49. Waddell, D., Creed, A., Cummings, T. G., Worley, C. G.: Organisational Change: Development and Transformation. Cengage AU (2016)

50. Wais-Zechmann, B., Gattol, V., Neureiter, K., Orji, R., Tscheligi, M.: Persuasive Technology to Support Chronic Health Conditions: Investigating the Optimal Persuasive Strategies for Persons with COPD. In International Conference on Persuasive Technology (pp. 255266). Springer, Cham (2018)

51. Wood, J.V.: What is Social Comparison and How Should We Study It? Personality and Social Psychology Bulletin, 22(5), 520-537 (1996)

52. Wood, W.: Attitude Change: Persuasion and Social Influence. Annual Review of Psychology 51(1), 539-570 (2000)

53. Wunsch, M., Stibe, A., Millonig, A., Seer, S., Dai, C., Schechtner, K., Chin, R.C.C.: What Makes You Bike? Exploring Persuasive Strategies to Encourage Low-Energy Mobility. In International Conference on Persuasive Technology (pp. 53-64). Springer, Cham (2015)

54. Zajonc, R.B.: Social Facilitation. Science, 149, pp. 269-274 (1965) 